\title{
Evaluation of Environmental Conditions on Self-Selected Work and Heat Stress in Wildland Firefighting
}

\author{
Joseph A. Sol, MS ${ }^{1}$; Molly R. West, $\mathrm{MPH}^{1}$; Joseph W. Domitrovich, $\mathrm{PhD}^{1}$; Brent C. Ruby, $\mathrm{PhD}^{2}$ \\ ${ }^{1}$ United States Department of Agriculture, Forest Service, National Technology and Development Program, Missoula, Montana; ${ }^{2}$ Montana Center \\ for Work Physiology and Exercise Metabolism, University of Montana, Missoula, Montana
}

\begin{abstract}
Introduction-The purpose of this study was to evaluate heat stress occurring in wildfire management activities with variable environmental conditions.

Methods-Direct observation and real-time wireless physiological monitoring allowed for weather and physiological metrics, including heart rate, core temperature $\left(\mathrm{T}_{\mathrm{c}}\right)$, skin temperature, and physiological strain index (PSI), of male $(n=193)$ and female $(n=28)$ wildland firefighters (WLFFs) to be recorded during wildfire management activities. Accelerometry data were used to categorize intensity level of activity.

Results-Ambient temperature and relative humidity values were used to compute the heat index $(\mathrm{HI} ; \mathrm{n}=3891 \mathrm{~h})$ and divided into quartiles $\left(\mathrm{Q} 1: 13.3-25.1^{\circ} \mathrm{C}\right.$; Q2: $25.2-26.4^{\circ} \mathrm{C}$; Q3: $26.5-28.9^{\circ} \mathrm{C}$; Q4: $\left.29.0-49.1^{\circ} \mathrm{C}\right)$. Activity levels remained relatively constant across all $\mathrm{HI}$ quartiles. The percentage of time spent performing moderate/vigorous activities was lowest during the hotter Q4 (Q1: 3\%; Q2: 2\%; Q3: 2\%; Q4: 1\%). Heart rate, $\mathrm{T}_{\mathrm{c}}, \mathrm{PSI}$, and skin temperature associations with $\mathrm{HI}$ varied by resource type. Sixty-one percent of WLFFs $(n=134)$ experienced a $T_{c} \geq 38.0^{\circ} \mathrm{C}$, and $50 \%$ of WLFFs $(n=111)$ experienced a PSI $\geq 6.0$.

Conclusions-Heat stress was prevalent as WLFFs performed job tasks of varying intensities in all ambient conditions. Spontaneous bouts of arduous labor, duration of work shifts, and other occupation characteristics present the possibility for substantial durations of hyperthermia, although no heat-related injuries occurred in this study. Despite chronic exposure to rugged sloped terrain, load carriage, and environmental conditions, self-regulation and individual attention to managing work:rest appears to be the primary management strategy in mitigating excessive accumulation of body heat in this occupation.
\end{abstract}

Keywords: hyperthermia, physiological strain

\section{Introduction}

According to the National Institute for Occupational Safety and Health, heat stress is the net heat load to which an individual is exposed as a result of the combination of metabolic heat, environmental factors, and clothing worn, which results in an increase in heat storage in the body. ${ }^{1}$ Heat stress can evoke heat strain, which is the physiological response to heat load. ${ }^{1}$ For wildland firefighters (WLFFs), the metabolic generation of heat is inevitable

Corresponding author: Joseph W. Domitrovich, PhD, National Technology and Development Program, US Forest Service, USDA, 5785 Highway $10 \mathrm{~W}$, Missoula, MT 59808; e-mail: joseph.domitrovich@usda.gov.

Submitted for publication August 2020.

Accepted for publication February 2021. as they hike over rough terrain, construct firelines, lay hose, operate chainsaws, and clear brush during wildfire management and training activities. ${ }^{2}$ These wildfire management activities are often performed in hot environments, which increases the associated strain on heat loss mechanisms during these activities. ${ }^{3}$ High values of water turnover $\left(4.5-9.6 \mathrm{~L} \cdot \mathrm{d}^{-1}\right)$ and caloric expenditure values ranging from 12.6 to $26.2 \mathrm{MJ} \cdot \mathrm{d}^{-1}$ (3000-6260 $\mathrm{kcal} \cdot \mathrm{d}^{-1}$ ) are further evidence of the strenuous physical requirements of a typical 12 to $14 \mathrm{~h}$ workshift. ${ }^{4-7}$

Studies have varied in description of tasks performed in the occupation; accelerometry data have demonstrated that WLFFs spend $49 \pm 8 \%, 39 \pm 6 \%$, and $12 \pm 2 \%$ of their workshifts in sedentary, light, and moderate-vigorous intensity categories, respectively. ${ }^{8}$ A more recent classification of these tasks using heart rate (HR) data suggests 
that WLFFs spend $43,9,19$, and $28 \%$ of their workshifts performing sedentary, light, moderate, and high-intensity physical activity. ${ }^{9}$ Correspondingly, these intensity levels of physical activity have shown increases in core temperature $\left(\mathrm{T}_{\mathrm{c}}\right)$ of $0.1,0.2$, and $0.4^{\circ} \mathrm{C}$ for light, moderate, and high-intensity tasks, respectively. ${ }^{9}$

Prior research has demonstrated that heat stress limits exercise performance $e^{10,11}$ and that social and behavioral factors often influence the intensity and duration of bouts of activity that WLFFs endure. ${ }^{12,13}$ Unfortunately, factors such as military or industrial discipline, commercial pressures, team effort, or personal motivation can deter a behavioral response to thermal stress. ${ }^{14}$ Although research in simulated environments can provide insight into the contributing factors that influence physiological strain, ${ }^{15-17}$ an emphasis on real-time documentation during wildfire suppression should become the primary driver of policy change because scripted laboratory or simulated data do not account for self-selected modifications to work rates in field settings. ${ }^{18}$ Although prior research has evaluated real-time physiological stress in WLFFs, these previous studies were conducted on only 2 fires in Colorado and Washington. ${ }^{7,8,19}$ The purpose of this study was to assess the real-time heat stress in WLFFs during wildfire management activities across variations in geographic and ambient weather conditions.

\section{Methods}

\section{PARTICIPANTS}

Participants were recruited on large wildfires in the western United States, where they typically work 14$\mathrm{d}$ shifts. Participants were asked to volunteer to be observed for 1 work shift on varied days of their respective assignments. Before taking part in the study, participants signed a written, informed consent form approved by a University of Montana institutional review board.

To obtain a comprehensive sample of the WLFF population, we included both interagency hotshot crews (IHCs) and other resource types (type II crews; 46 and 54\% of the total sample, respectively). On wildfire incidents, IHCs are a common type I, or typically more experienced, resource, usually composed of 20 to 22 crewmembers. In contrast, other resource types can range from 3 to 20 crewmembers, depending on their purpose. ${ }^{20}$

\section{EXPERIMENTAL DESIGN}

Field data were collected during the fire season (May to October) in the western United States from 2013 through 2016. Before data collection, the US Department of
Agriculture-Forest Service's National Technology and Development Program trained a cohort of WLFFs in direct observation methodologies. Continuous observations of each participant permitted the research team to classify tasks and relate physiological responses to each specific task a participant performed using this methodology, as seen in prior studies. ${ }^{9,21}$ Participants were allowed to eat and drink ad libitum throughout the day.

On the morning of each trial $(\approx 0600), 2$ or 3 participants from a WLFF resource type arrived at the field laboratory after an overnight fast and ingested an initialized wireless thermometer capsule (Jonah ingestible sensor, Mini Mitter, Bend, OR). Participants were fitted with a Hidalgo Equivital physiological monitor, which communicates with the thermometer capsule and records HR and skin temperature $\left(\mathrm{T}_{\mathrm{sk}}\right)$. This device consists of a chest harness with shoulder straps worn around the chest to situate sensors inferior to the pectoral muscles on the anterior chest surface. Participants then ate breakfast before their workshift to promote $\mathrm{T}_{\mathrm{c}}$ capsule progression into the digestive tract.

\section{PHYSICAL MEASUREMENTS}

The Hidalgo Equivital physiological monitor continuously monitored and recorded $\mathrm{HR}, \mathrm{T}_{\mathrm{c}}$, and $\mathrm{T}_{\mathrm{sk}}$ throughout the entire workshift using the previously mentioned methodology. Raw $H R, \mathrm{~T}_{\mathrm{c}}$, and $\mathrm{T}_{\mathrm{sk}}$ values were trimmed according to the $\mathrm{CI}$ associated with the Hidalgo physiological monitor. A threshold of $85 \%$ CI was used based on manufacturer recommendations and evaluation of raw data. The data above $85 \%$ CI consisted of values associated with population and age-adjusted normal values. Maximal HR $\left(\mathrm{HR}_{\max }\right)$ was estimated using the equation $\mathrm{HR}_{\max }=208-0.7 \times$ age. $^{22}$

An Atago 4410 PAL-10S digital pocket refractometer was used to measure urine specific gravity (USG). Before each shift, a first void urine sample was collected from each participant to provide a baseline USG. Before the evening meal, another void sample was obtained from each participant to measure post-shift USG in the fire camp.

Equipment weight was obtained using a calibrated digital scale (Taylor Precision Products, Model 7329B, Oakbrook, IL) set on a stable, level surface, and values were recorded in $0.1 \mathrm{lb}$ increments and converted to kilograms. Bodyweight (including shirt, pants, and fire boots; approximate weight $=4 \mathrm{~kg}$ ) was subtracted from the total ensemble weight to calculate equipment weight. Equipment ensembles were independently verified throughout the workshift using photographs taken during direct observation of the participant and using aircraft manifest weight estimates of the equipment. ${ }^{20}$ Participant 
height was self-reported, and body surface area was calculated using the participant height and body weight in the following equation ${ }^{23}$ :

$$
\operatorname{BSA}\left(\mathrm{m}^{2}\right)=\sqrt{ }[(\text { height in } \mathrm{cm} \times \text { weight in } \mathrm{kg}) / 3600]
$$

\section{CRITERIA FOR PHYSIOLOGICAL HEAT STRAIN}

$A \mathrm{~T}_{\mathrm{c}}$ of $38.0^{\circ} \mathrm{C}$ was used as a threshold for increased risk of heat stress. ${ }^{1}$ As an additional measure to evaluate conditions of heat stress, the physiological strain index (PSI) was used to quantify the heat strain experienced by each participant using the following equation ${ }^{24}$ :

$\mathrm{PSI}=5 \times\left(\mathrm{T}_{\mathrm{c}(\mathrm{t})}-\mathrm{T}_{\mathrm{c}(0)}\right) \times\left(39.5-\mathrm{T}_{\mathrm{c}(0)}\right)^{-1}+5 \times\left(\mathrm{HR}_{(\mathrm{t})}-\mathrm{HR}_{(0)}\right) \times$ $\left(180-\mathrm{HR}_{(0)}\right)^{-1}$

$\mathrm{T}_{\mathrm{c}(0)}$ and $\mathrm{HR}_{(0)}$ were the initial $\mathrm{T}_{\mathrm{c}}$ and HR measured at the start of the workshift. $\mathrm{T}_{\mathrm{c}(\mathrm{t})}$ and $\mathrm{HR}_{(\mathrm{t})}$ were the $\mathrm{T}_{\mathrm{c}}$ and HR values corresponding to a given time point. PSI $^{25,26}$ was based on $\mathrm{T}_{\mathrm{c}}$ and HR values, a valid expression of thermoregulatory load. A PSI $\geq 6.0$ is recognized as the onset of marginal risk of heat injury due to high heat stress levels from exercise and can be associated with a $\mathrm{T}_{\mathrm{c}}$ of $38.3^{\circ} \mathrm{C} .^{24-26}$

\section{ACTIVITY MONITORS}

ActiCal activity monitors (MiniMitter, Bend, OR) were used to record activity counts (ACT). The monitors were initialized and distributed to participants to determine ACT during $1 \mathrm{~d}$ of firefighting. The activity monitor was placed in the left chest pocket of the Nomex fire shirt, similar to prior studies. ${ }^{27}$ The pectoral location was chosen because of the amount of upper body movement associated with firefighting. For protection and stability, each monitor was secured in a cardboard square $(\sim 8 \times 8$ $\mathrm{cm})$. ACT data (counts $\cdot \mathrm{min}^{-1}$ ) were divided into 3 intensity ranges: sedentary $\left(0-99\right.$ counts $\left.\cdot \mathrm{min}^{-1}\right)$, light $\left(100-1499\right.$ counts $\left.\cdot \mathrm{min}^{-1}\right)$, and moderate/vigorous $\left(\geq 1500\right.$ counts $\left.\cdot \mathrm{min}^{-1}\right) \cdot{ }^{27,28}$

\section{AMBIENT TEMPERATURE AND RELATIVE HUMIDITY}

An OMEGA temperature data logger (OMEGA Engineering, Inc., Stamford, CT) was attached to the shoulder strap on each participant's fireline pack to record ambient temperature and relative humidity $(\mathrm{RH})$ at minute intervals throughout the workshift. Heat index (HI) values were calculated using temperature and $\mathrm{RH}$ inputs and adjustments using the method described in prior studies. ${ }^{29}$ Temperature and RH values when the participant was riding in vehicles were removed from the data set, and the remaining data were then used to compute HI $(\mathrm{n}=141,785 \mathrm{~min})$ and allocated into quartiles (Q1: $13.3-25.1^{\circ} \mathrm{C}$; Q2: $25.2-26.4^{\circ} \mathrm{C}$; Q3: $26.5-28.9^{\circ} \mathrm{C}$; $\mathrm{Q} 4: 29.0-49.1^{\circ} \mathrm{C}$ ) to evaluate ambient conditions and their relationship with a measured physiological response.

\section{STATISTICS}

Data are presented as mean $\pm \mathrm{SD}$ or percentages to describe the distribution of time spent at various activity levels. Independent-sample t-tests were used to analyze differences in study variables between resource types and HI quartiles with SPSS statistics software (SPSS Inc., Chicago, IL). $P<0.05$ was considered significant. Levene's test for equality of variances was used to check assumptions of equal variance before inference procedures were used on the response variables.

\section{Results}

\section{DESCRIPTIVE DATA}

Male $(\mathrm{n}=193 ; 27 \pm 6 \mathrm{y} ; 179 \pm 9 \mathrm{~cm} ; 86.0 \pm 11.8 \mathrm{~kg})$ and female $(\mathrm{n}=28 ; 26 \pm 4 \mathrm{y} ; 167 \pm 9 \mathrm{~cm} ; 68.6 \pm 8.4 \mathrm{~kg})$ WLFFs participated in this study (see Table 1 for participant age, height, weight, body mass index, equipment weight, and body surface area $[\mathrm{BSA}]^{23}$ ). Age, height, and BSA did not differ by resource type. IHCs carried more equipment weight than type II resources (difference of $2.3 \mathrm{~kg}$; $P<0.05$ ), and females' equipment weight was a significantly larger percentage of body weight compared with males (females $=27 \%$ of bodyweight; males $=22 \%$ : $P<0.05)$.

\section{AMBIENT CONDITIONS}

Observation days $(n=167)$ consisted of wildfire management activities on 50 wildfire incidents. As such, the environmental conditions varied widely by geographic location and season. WLFFs in this study experienced ambient temperatures exceeding $30.4^{\circ} \mathrm{C}\left(\approx 87^{\circ} \mathrm{F}\right)$ in $20 \%$ of the data set. The highest observed ambient temperature was $50.3^{\circ} \mathrm{C}\left(\approx 123^{\circ} \mathrm{F}\right)$, and $30 \%$ of WLFFs in the study experienced a maximal ambient temperature higher than $37.7^{\circ} \mathrm{C}\left(\approx 100^{\circ} \mathrm{F}\right)$ while assigned to a wildfire incident. In WLFF communities, 1400 is a critical time point for changes in fire behavior. Wildland fire management activities thus occur in preparation for this time of day but can also change at this time of day as well, dictated by the fire's behavior. The distribution by state of mean ambient temperature and $\mathrm{RH}$ values at 1400 is reported in Figure 1 . The mean ambient temperature and $\mathrm{RH}$ recorded at 1400 was $29.5 \pm 6.5^{\circ} \mathrm{C}\left(\approx 85^{\circ} \mathrm{F}\right)$ and $28 \pm 15 \%$, respectively. 


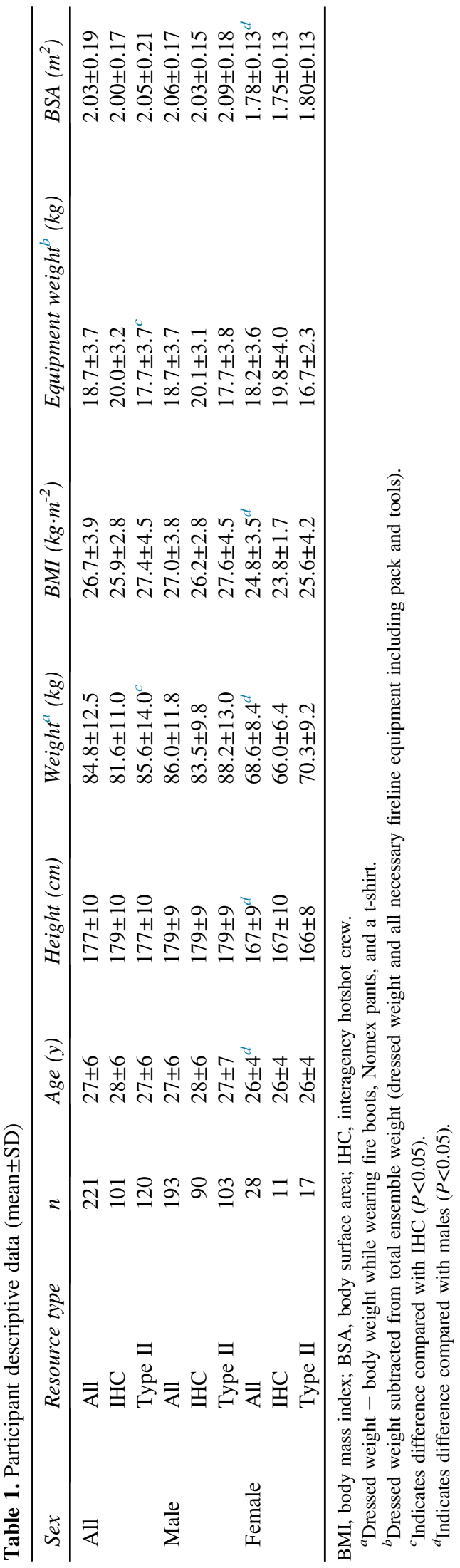

\section{ACTIVITY COUNTS}

Participants in the study spent $67,61,62$, and $64 \%$ of their time performing sedentary activities $\quad(<100$ counts. $\mathrm{min}^{-1}$ ) in Q1, Q2, Q3, and Q4, respectively. The percentage of time spent carrying out light-intensity activities increased slightly from Q1 to Q2, Q3, and Q4 (Figure 2). Time spent executing moderate and vigorous activities decreased by $67 \%$ from Q1 to Q4 (3\% to $1 \%$; $P<0.05$ ).

When considering overall activity (all levels of activity including sedentary; $n=49,871 \mathrm{~min}$ ), activity levels for IHCs were highest in Q2 and Q3, with lower activity counts observed in Q1 and Q4 (Figure 3). For type II resources, Q1, Q2, and Q3 activity values were higher than Q4 $(P<0.05)$. When evaluating physical activity only (ACT $>100$ counts $\left.\cdot \mathrm{min}^{-1} ; \mathrm{n}=30,957 \mathrm{~min}\right), \mathrm{Q} 1, \mathrm{Q} 2$, and Q3 activity values were all higher than Q4 $(P<0.05)$. Overall activity for Type II resources ( $\mathrm{n}=31,672 \mathrm{~min})$ displayed a negative correlation between ACT and HI quartiles, although only Q1 and Q2 activity values were higher than Q4 $(P<0.05)$. When evaluating physical activity only (ACT $>100$ counts $\cdot \mathrm{min}^{-1} ; \mathrm{n}=19,580$ ), only Q1 and Q2 activity values were higher than Q4 $(P<0.05)$. Resource type differences existed only for Q1 and Q3 $(P<0.05$; Figure 3$)$.

\section{THERMOREGULATORY VARIABLES}

Mean peak HR values for all subjects was $171 \pm 25$ beats $\cdot \min ^{-1}$. When considering physical activity alone, mean HR values for IHCs displayed a positive correlation with HI quartiles $(108 \pm 24,114 \pm 23,115 \pm 23$, and $119 \pm 23$ beats. $\mathrm{min}^{-1}$ for $\mathrm{Q} 1, \mathrm{Q} 2, \mathrm{Q} 3$, and $\mathrm{Q} 4$, respectively.) Q1, $\mathrm{Q} 2$, and Q3 IHC mean HR values were significantly less than Q4 HR values $(P<0.05)$. Conversely, mean HR values for type II resources for Q1, Q2, and Q3 were all significantly higher than Q4 HR values $(115 \pm 26$, $112 \pm 23,111 \pm 22,108 \pm 19$ beats $\cdot \mathrm{min}^{-1}$ for Q1, Q2, Q3, and $\mathrm{Q} 4$, respectively; $P<0.05$ ). Mean $\mathrm{HR}$ values were significantly different between resource types at all $\mathrm{HI}$ quartiles $(P<0.05)$.

$\mathrm{T}_{\mathrm{c}}$ and PSI values are reported in Figure 4. Briefly, $\mathrm{T}_{\mathrm{c}}$ showed a positive correlation with HI quartiles for IHCs, with mean IHC $\mathrm{T}_{\mathrm{c}}$ for $\mathrm{Q} 4$ being significantly greater than for all other quartiles $(P<0.05)$. Type II resources displayed a weaker association between $\mathrm{T}_{\mathrm{c}}$ and $\mathrm{HI}$ quartiles, where mean $\mathrm{T}_{\mathrm{c}}$ for only $\mathrm{Q} 1$ and $\mathrm{Q} 3$ was different from Q4 values $(P<0.05)$. IHC mean PSI values for $\mathrm{Q} 1, \mathrm{Q} 2$, and Q3 were less than those in Q4 $(P<0.05)$, whereas only the mean PSI values for Q2 were different from Q4 values for Type II resources $(P<0.05)$. All quartile values of $\mathrm{T}_{\mathrm{c}}$ and PSI were significantly different between resource types except for the $\mathrm{T}_{\mathrm{c}}$ values of Q2 $(P<0.05)$. 


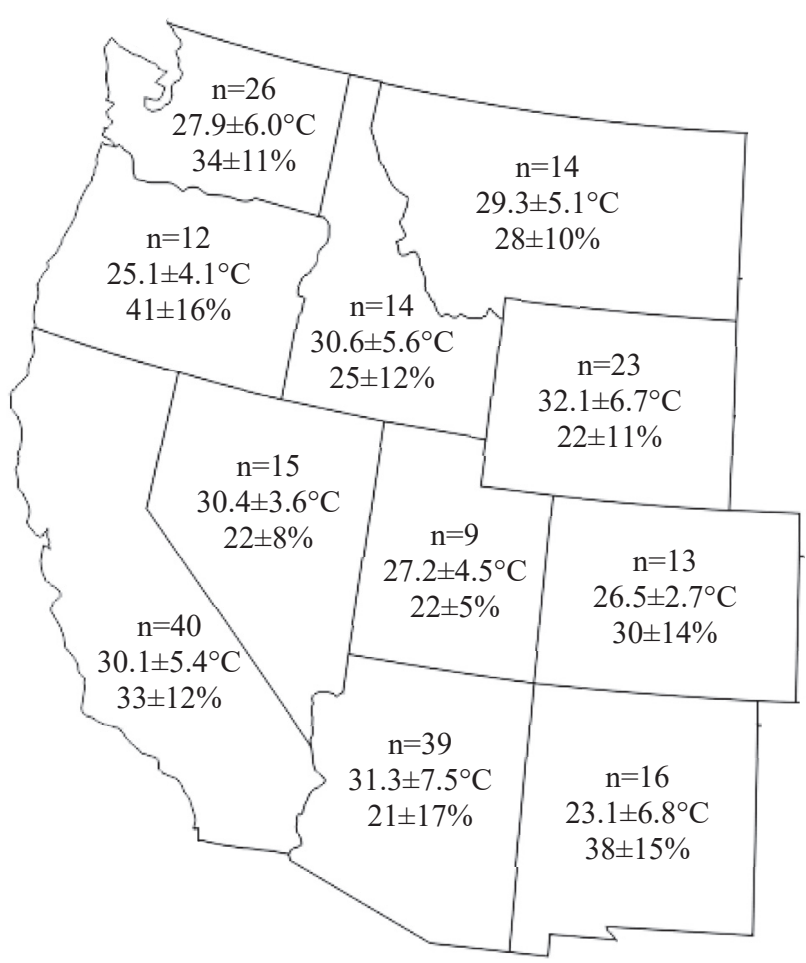

Figure 1. Map of the western continental United States with the number of study participants, mean ambient temperature, and relative humidity from data collection sites in each state at 1400 . In wildland firefighting communities, a critical time point for changes in fire behavior is 1400 . Wildland fire management activities thus occur in preparation for this time of day but can also change at this time of day as well, dictated by the fire's behavior.

Nearly $61 \%$ of WLFFs $(n=134)$ experienced a $T_{c}$ $\geq 38.0^{\circ} \mathrm{C}$; 93 of these individuals experienced this elevated $\mathrm{T}_{\mathrm{c}}$ for $>30 \mathrm{~min}$ (average frequency $=97 \mathrm{~min}$ ). Comparatively, $50 \%$ of WLFFs $(\mathrm{n}=111)$ experienced a PSI $\geq 6.0 ; 37$ participants experienced this elevated PSI for $>30 \mathrm{~min}$.

IHC $\mathrm{T}_{\mathrm{sk}}$ in Q4 was significantly higher than in all other quartiles $(31.7 \pm 1.9,31.9 \pm 2.0,32.2 \pm 2.1$, and $33.1 \pm 2.0^{\circ} \mathrm{C}$ for $\mathrm{Q} 1, \mathrm{Q} 2, \mathrm{Q} 3$, and $\mathrm{Q} 4$, respectively; $P<0.05$ ). Type II resource $\mathrm{T}_{\mathrm{sk}}$ in $\mathrm{Q} 4$ was also significantly higher than in all other quartiles $(31.9 \pm 1.9$, $32.3 \pm 2.0,32.8 \pm 1.8$, and $33.3 \pm 2.0^{\circ} \mathrm{C}$ for Q1, Q2, Q3, and $\mathrm{Q} 4$, respectively; $P<0.05)$. Type II $\mathrm{T}_{\mathrm{sk}}$ values were higher than IHC values across all $\mathrm{HI}$ quartiles $(P<0.05)$.

\section{HYDRATION STATUS}

The range of first void USG values (mean $=1.017 \pm 0.007$; Figure 5) displays the prevalence of a wide variation in estimated hydration status among WLFFs before their respective workshifts. Similar post-shift values $(1.015 \pm 0.008)$ were observed.

\section{Discussion}

This study establishes that WLFFs typically operate at $T_{c}$ values elevated above resting values throughout the workshift in a wide array of ambient conditions. Twenty percent of the ambient conditions in this study correspond with moderate- to very high-risk conditions for heat stress, according to industrial and military guidelines. ${ }^{30}$ Despite these conditions, mean $\mathrm{T}_{\mathrm{c}}$ and $\mathrm{T}_{\mathrm{sk}}$ values displayed only a mild association with ambient conditions. When accompanied by the abnormal performance of 1 or more organ systems, a $\mathrm{T}_{\mathrm{c}} \geq 38.0^{\circ} \mathrm{C}$ is defined by the National Institute for Occupational Safety and Health as heat exhaustion. ${ }^{1}$ Of note, nearly two-thirds of participants $(61 \%)$ experienced a $\mathrm{T}_{\mathrm{c}} \geq 38.0^{\circ} \mathrm{C}$, whereas a lower percentage (50\%) experienced a PSI $\geq 6.0$, which can be associated with a $\mathrm{T}_{\mathrm{c}}$ of $38.3^{\circ} \mathrm{C} \cdot{ }^{24-26}$ This difference is likely due to the impact of low heart rates in the PSI calculation that may minimize the estimated heat strain. Although these individuals did not report symptoms or incidence of heat-related injury, hyperthermia prevalence and duration are significant. Furthermore, this study established that although moderate and arduous activity levels are tempered during elevated HI, activity is performed in all ambient conditions.

The occupation of wildland firefighting presents a unique and diverse set of challenges for individuals from a physiological perspective. As evidenced in Figure 1, WLFFs can expect summer campaigns of 14-d assignments, each with a unique environmental profile. Furthermore, WLFFs demonstrate a wide array of USG values, suggesting large variations in estimated pre-shift hydration status. Despite significant water turnover values documented in prior studies, USG values were comparable between pre-shift and post-shift collection points. $^{4,5,12,19}$ However, it is essential to acknowledge that $17 \%$ of WLFFs began and ended the workshift with a USG $>1.025$ (Figure 5). Although a single measure of USG, particularly a first void measurement, does not clearly demonstrate dehydration, this array of values supports the promotion of diligent hydration practices throughout the day in this population.

Accelerometry data demonstrated that the percentage of time spent in sedentary, light, and moderate/vigorous intensity activity remained relatively constant across all ambient conditions. Because no evidence of heat-related injuries was found in the study, these results suggest a propensity toward self-regulation of physical activity to 


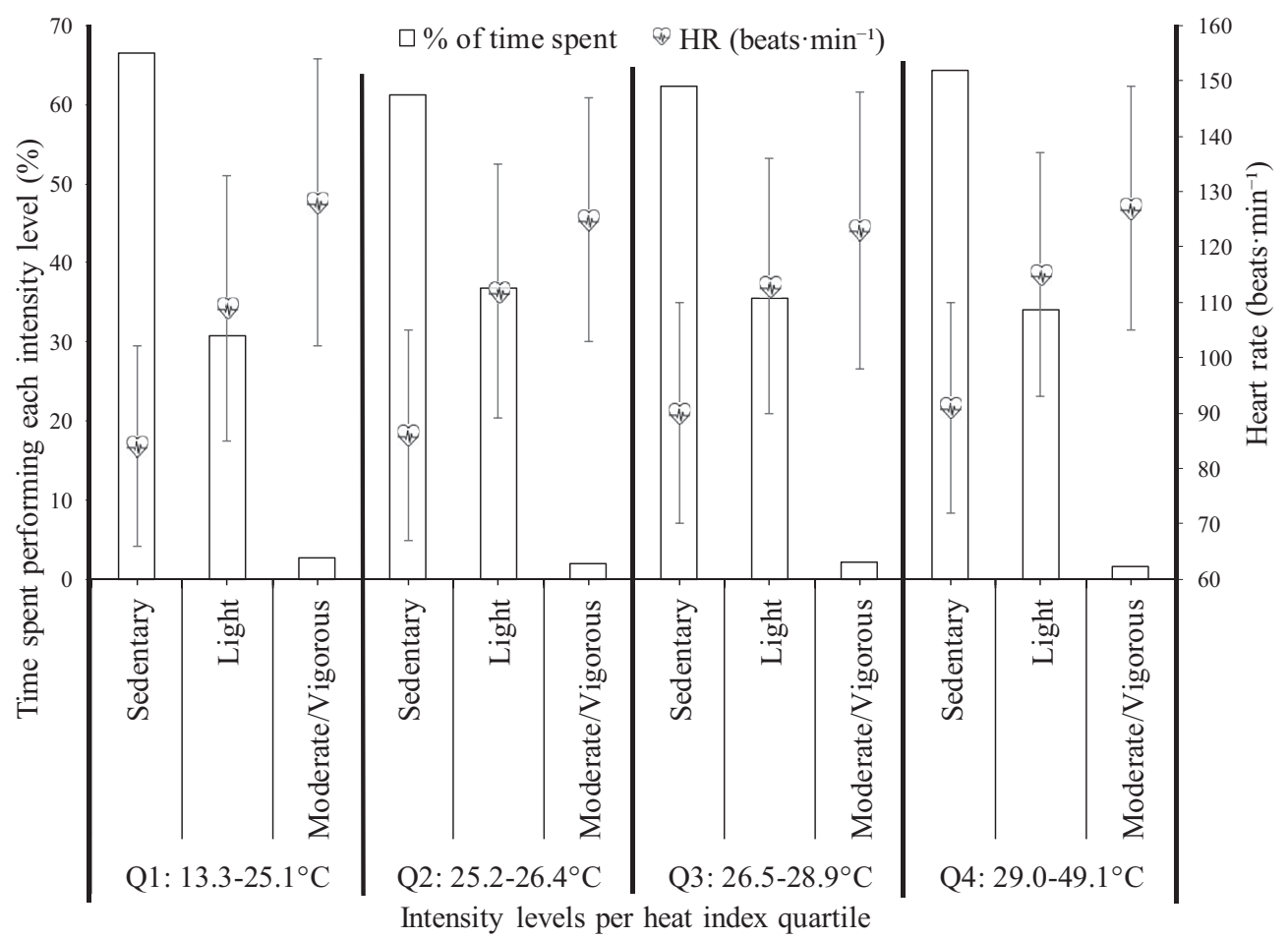

Figure 2. Combination bar and line graph displaying the distribution of time spent at each intensity level across all heat index quartiles and the associated heart rate at each intensity.

manage body temperature in most WLFF field operations, similar to conclusions in Australian WLFF populations. ${ }^{18}$ Key principles that have been previously suggested to mitigate heat strain during fire suppression activities include avoiding unnecessary heat and encouraging self-pacing, drinking fluids, and allowing sweat to evaporate. ${ }^{18}$

The activity level and equipment weight both contributed to conditions of physiological strain that can be self-regulated. Of specific interest in this population, muscle work results in body heat, with more than $70 \%$ of metabolic energy converted to heat during physical activity. ${ }^{31-35}$ The demand of job tasks performed on the fireline is likely further influenced by the weight of equipment carried $(18.7 \pm 3.7$ $\mathrm{kg}$ for all resource types; Table 1) and hot temperatures associated with wildfire conditions. Supported by the HR and $T_{c}$ values observed in this study, regulating the duration of high-intensity activities, management of work:rest guidelines during operations, and promoting aerobic fitness in this population should be emphasized. Interestingly, HR displayed a negative correlation with $\mathrm{HI}$ for Type II resources in the study, whereas HR showed a positive correlation with HI for IHCs. Differences in WLFF resource utilization likely influence these results; the different resource types may receive various tasks in response to higher ambient conditions and fire activity. Although this study observed a decrease in the percentage of time spent performing moderate and vigorous activity from Q1 to Q4 (67\% reduction in accelerometer data), it is essential to note that increased ambient conditions may result in increased fire activity, which can impede wildfire management activities. This concept and its effect on WLFF tactics may contribute to managing physiological strain in these individuals.

As in prior WLFF studies, ${ }^{2}$ hiking was a critical metabolic contributor to heat loading in these tactical athletes (Figure 6). The initial hike into the fire or work unit generally raises an individual's body temperature significantly and may result in elevated body temperature for several hours afterward. ${ }^{8,9,22}$ Because these hikes occur before the physical labor portion of the workshift, the crew transports their equipment for the entire shift during this hike. This initial hike (typically $20-60 \mathrm{~min}$ in duration) also often occurs during a part of the day (usually between 0730 and 1100) when ambient temperatures are rising, and $\mathrm{RH}$ may not have decreased to respective afternoon values $\left(21.9 \pm 6.2^{\circ} \mathrm{C}\right.$ and $41 \pm 15 \%$, respectively).

Mitigation strategies for WLFFs should include reducing equipment weights for resources working in hot 


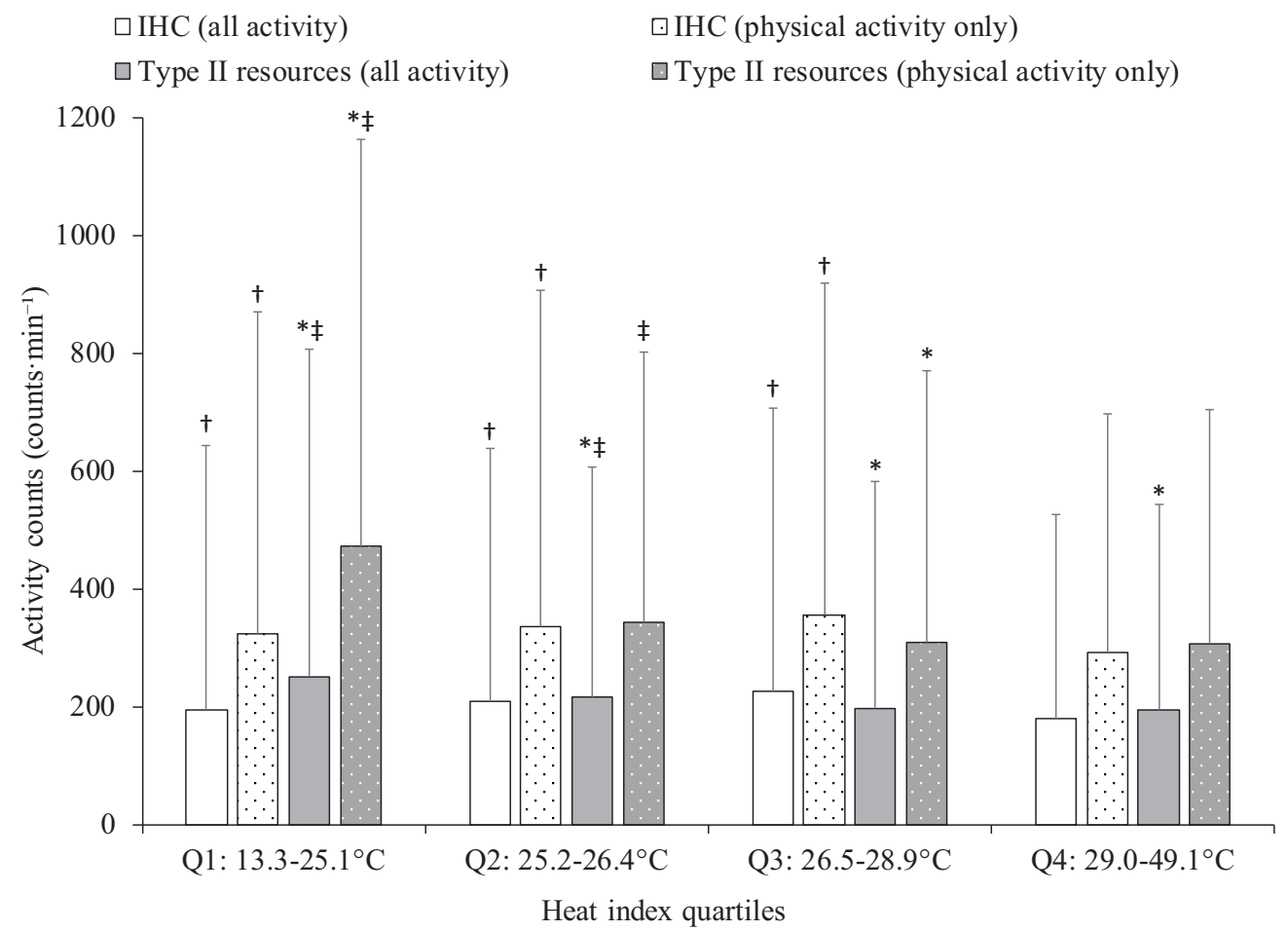

Figure 3. Bar graph displaying the mean activity counts for both resource types in each heat index quartile. Activity was divided into all activities and physical activity only, defined as activity counts exceeding 100 counts $\min ^{-1}$. * - indicates a difference from IHC $(P<0.05) ; \dagger-$ indicates difference from Q4 of IHC data $(P<0.05) ; \ddagger$ - indicates difference from Q4 of type II data $(P<0.05)$.

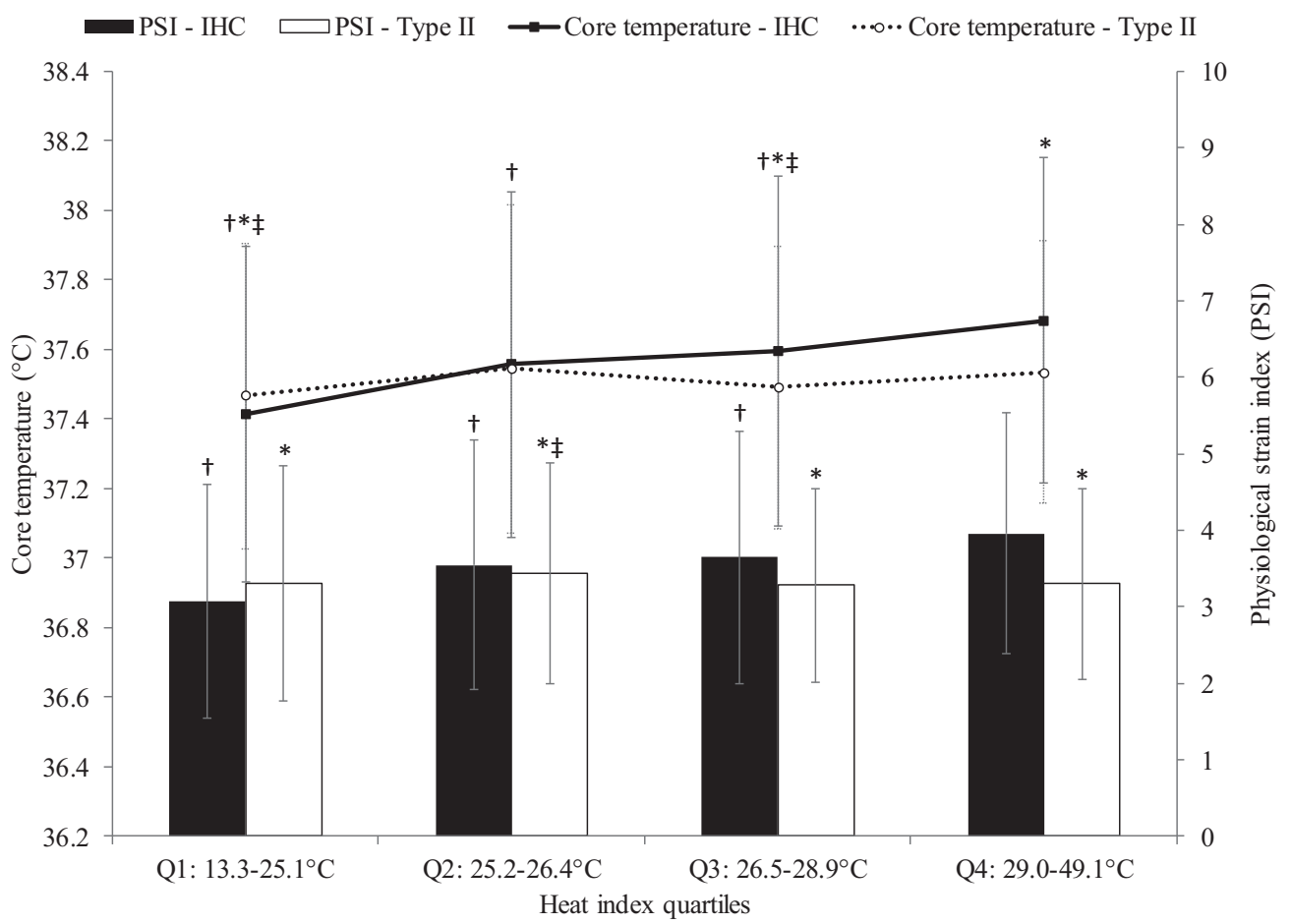

Figure 4. Combination bar and line graph displaying the core temperature and physiological strain index values for each resource type in each heat index quartile. * - indicates a difference from IHC $(P<0.05) ; \dagger$ - indicates difference from Q4 of IHC data $(P<0.05)$; $\ddagger$ - indicates difference from Q4 of type II data $(P<0.05)$. 


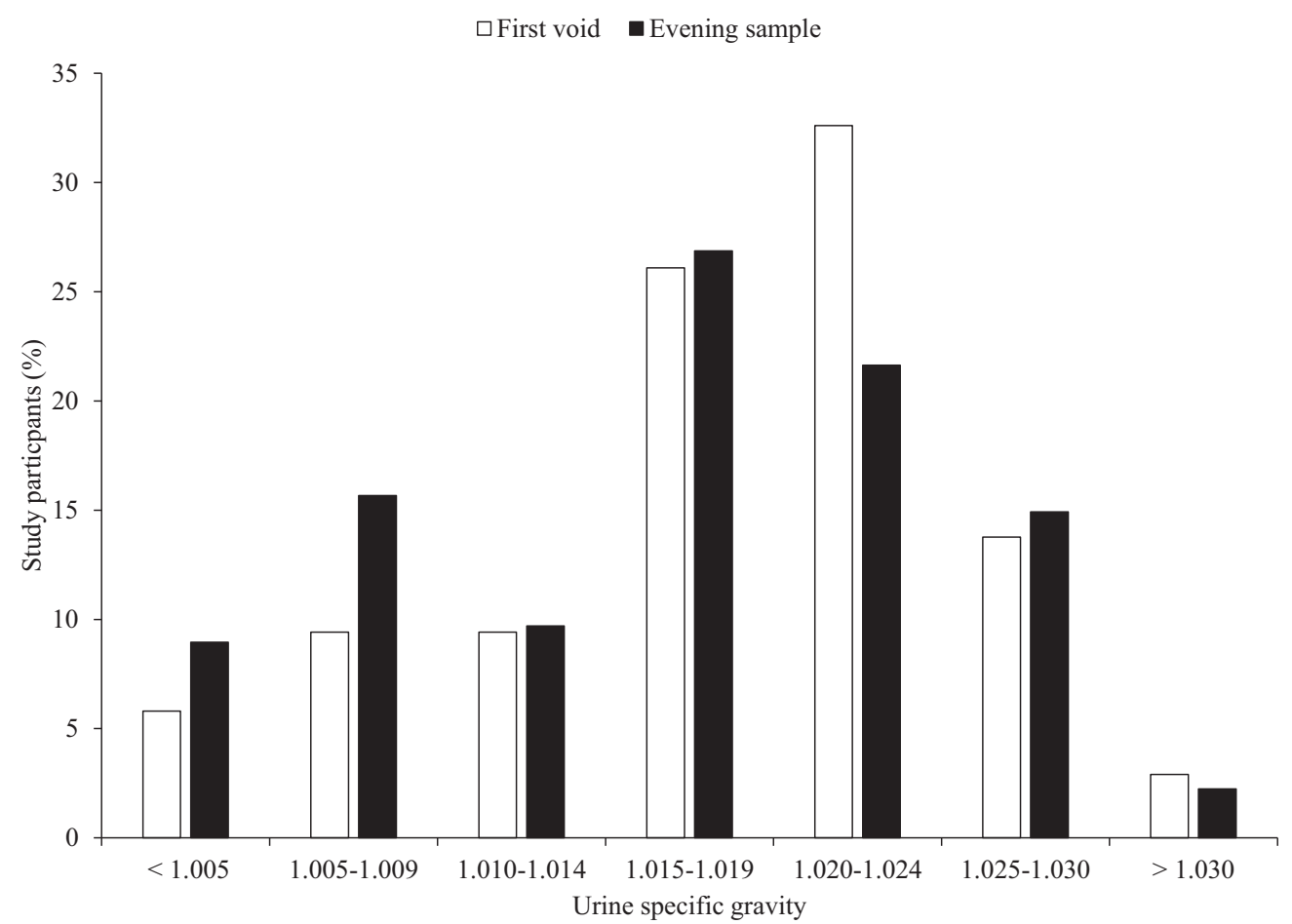

Figure 5. Graph showing the distribution of first void and post-shift urine specific gravity measurements collected in the study.

temperatures; equipment weights over $25 \%$ of an in- heat illness during activity. ${ }^{37,38}$ As such, to better prepare dividual's bodyweight significantly increase the demand of all activities performed. ${ }^{36}$ Fitter males have been shown to have a substantially lower risk for exertional individuals for the demands of wildfire management and training activities, preparation should emphasize developing aerobic capacity through aerobic training and heat

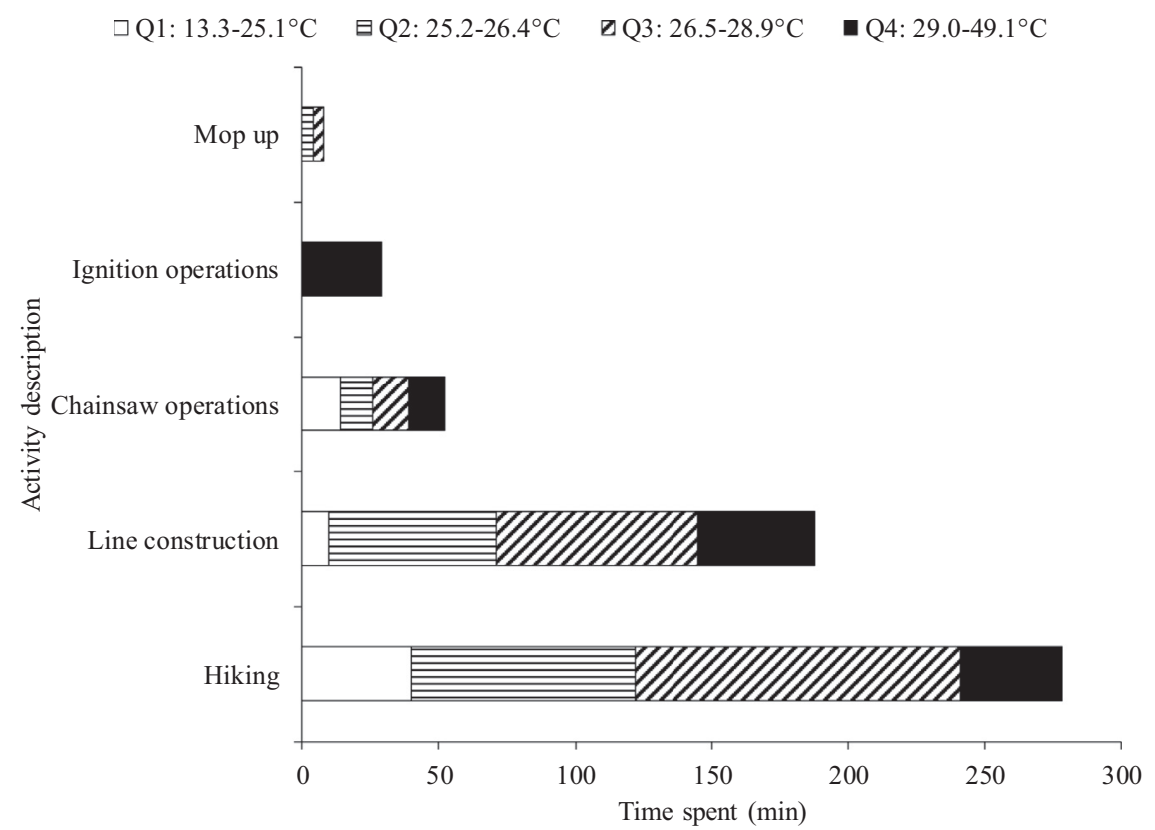

Figure 6. Stacked bar graph showing the frequency of everyday wildland firefighter job tasks that occurred in conditions in which physiological strain index exceeded 6.0. Each bar graph shows the frequency of each activity in each heat index quartile. 
acclimation strategies, such as light to moderate exercise in hot climates, with adequate rest in colder conditions afterward. ${ }^{39}$ These training programs should also implement increasing aerobic capacity and pacing strategies, such as work:rest, for the crew as a whole and individual members to prepare for the long, chronic effects of fire season activities. ${ }^{8,9,22,37}$ Moreover, these factors should be emphasized at a higher priority than aggressive fluid delivery strategies; prior research has documented heatrelated injury in a WLFF despite significant water consumption. ${ }^{8}$ Recent research has also reported that the mean WLFF breakfast and shift provision intake provides adequate electrolyte replacement, without the use of supplements, for most workshifts. ${ }^{40}$

\section{LIMITATIONS}

Data collected for this study were from different WLFFs during different seasons. Participants were not selected at random; they were recruited from available resources in the fire camps and asked to volunteer for the study. There is a lack of female representation in this occupation, ${ }^{2}$ and our results do not address sex differences for multiple variables. No preliminary testing of the participants was conducted because of each participating crew's location across the Western United States. As stated in the Methods, participants typically had at least $1 \mathrm{~d}$ of work before participation, and the number of days worked by WLFFs before participation varied. The nature of the field research did not allow us to control the number of days previously worked. As such, these data do not consider the effects of previously worked shifts on the observed physiological response.

WLFFs often have different daily assignments while on an incident for multiple weeks. Typical workdays can include 10 to 30 or more activities (eg, hiking, digging, briefing, rest) per workshift. After the morning ingress hike, which the crew performs together, tasks/activities are distributed among crewmembers to achieve the operational assignment for that workshift. Assignment distribution changes the total daily energy expenditure across crewmembers and may reduce some crewmembers' higher intensity workload relative to others.

Because food and water consumption was ad libitum and not recorded, caloric ingestion and hydration status variations may affect thermoregulation and activity attributes. Furthermore, food and water consumption may have affected $T_{c}$ readings during the workshift. There is also the potential for error in the Hidalgo unit's infrared $\mathrm{T}_{\mathrm{sk}}$ sensor because the shoulder straps and other equipment donned by WLFFs may interfere or interact with the placement and reading of the variable.

\section{Conclusions}

WLFFs performed job tasks of varying intensities in all ambient conditions, with significant portions of the workshift at elevated heat strain risk. Most of the activity occurring during a workshift can be characterized as sedentary or light intensity. However, spontaneous bouts of arduous labor, duration of work shifts, and other occupation characteristics present the possibility for a substantial duration of hyperthermia. Despite these demanding work conditions, no heat-related injuries occurred in this study. Variations in physiologic variables between resource types are likely due to latent variables associated with occupational assignments and leadership. Despite chronic exposure to rugged sloped terrain, load carriage, and environmental conditions, self-regulation and individual attention to managing work:rest appear to be the primary strategy in mitigating excessive accumulation of body heat in this occupation.

Acknowledgments: The authors thank the participants for their investment of time and energy. Additionally, we extend our gratitude to the cohort of field researchers for their assistance in field observations.

Author Contributions: Conception: JAS, JWD, BCR; design: (JAS, JWD, BCR); data acquisition (JAS, MRW, JWD), interpretation of data (JAS, MRW, JWD, BCR); drafting manuscript (JAS, BCR); revision and approval of manuscript (JAS, MRW, JWD, BCR).

Financial/Material Support: This study was supported by funding from the US Department of Agriculture and Forest Service Fire and Aviation Management Group in addition to the National Wildfire Coordination Group, US Department of Interior, Bureau of Land Management, National Park Service, Fish and Wildlife Service, and the Bureau of Indian Affairs.

Disclosures: None.

\section{References}

1. Jacklitsch BL, Williams WJ, Musolin K, Coca A, Kim J-H, Tuner N. NIOSH criteria for a recommended standard: occupational exposure to heat and hot environments. US Dept of Health and Human Services, Centers for Disease Control and Prevention; 2016. Publication No. 2016-106.

2. Sol J, Ruby B, Gaskill S, Dumke C, Domitrovich J. Metabolic demand of hiking in wildland firefighting. Wilderness Environ Med. 2018;29(3):304-14.

3. Cheung SS, McLellan TM, Tenaglia S. The thermophysiology of uncompensable heat stress. Physiological manipulations and individual characteristics. Sports Med. 2000;29(5):329-59.

4. Ruby BC, Shriver TC, Zderic TW, Sharkey BJ, Burks C, Tysk S. Total energy expenditure during arduous wildfire suppression. Med Sci Sports Exerc. 2002;34(6):1048-54.

5. Ruby BC, Schoeller DA, Sharkey BJ, Burks C, Tysk S. Water turnover and changes in body composition during arduous wildfire suppression. Med Sci Sports Exerc. 2003;35(10):1760-5. 
6. Cuddy JS, Slivka DR, Tucker TJ, Hailes WS, Ruby BC. Glycogen levels in wildland firefighters during wildfire suppression. Wilderness Environ Med. 2011;22(1):23-7.

7. Cuddy JS, Sol JA, Hailes WS, Ruby BC. Work patterns dictate energy demands and thermal strain during wildland firefighting. Wilderness Environ Med. 2015;26(2):221-6.

8. Cuddy JS, Ruby BC. High work output combined with high ambient temperatures caused heat exhaustion in a wildland firefighter despite high fluid intake. Wilderness Environ Med. 2011;22(2):122-5.

9. West MR, Costello S, Sol JA, Domitrovich JW. Risk for heat-related illness among wildland firefighters: job tasks and core body temperature change. Occup Environ Med. 2020;77(7):433-8.

10. Montain SJ, Sawka MN, Cadarette BS, Quigley MD, McKay JM. Physiological tolerance to uncompensable heat stress: effects of exercise intensity, protective clothing, and climate. J Appl Physiol (1985). 1994;77(1):216-22.

11. Sawka MN, Young AJ, Latzka WA, Neufer PD, Quigley MD, Pandolf KB. Human tolerance to heat strain during exercise: influence of hydration. J Appl Physiol (1985). 1992;73(1):368-75.

12. Rodríguez-Marroyo JA, López-Satue J, Pernía R, Carballo B, Garcia-Lopez J, Foster C, et al. Physiological work demands of Spanish wildland firefighters during wildfire suppression. Int Arch Occup Environ Health. 2012;85(2):221-8.

13. Rodríguez-Marroyo JA, Villa JG, López-Satue J, Pernia R, Carballo B, Garcia-Lopez J, et al. Physical and thermal strain of firefighters according to the firefighting tactics used to suppress wildfires. Ergonomics. 2011;54(11):1101-8.

14. Budd GM. Wet-bulb globe temperature (WBGT)-its history and its limitations. J Sci Med Sport. 2008;11(1):20-32.

15. Carballo-Leyenda B, Villa JG, Lopez-Satue J, Collado PS, Rodriguez-Marroyo JA. Fractional contribution of wildland firefighters' personal protective equipment on physiological strain. Front Physiol. 2018;9:1139.

16. Carballo-Leyenda B, Villa JG, López-Satué J, RodríguezMarroyo JA. Impact of different personal protective clothing on wildland firefighters' physiological strain. Front Physiol. 2017;8:618.

17. Williams-Bell FM, Aisbett B, Murphy BA, Larsen B. The effects of simulated wildland firefighting tasks on core temperature and cognitive function under very hot conditions. Front Physiol. 2017;8:815.

18. Budd GM. How do wildland firefighters cope? Physiological and behavioural temperature regulation in men suppressing australian summer bushfires with hand tools. J Therm Biol. 2001;26(4):381-6.

19. Cuddy JS, Ham JA, Harger SG, Slivka DR, Ruby BC. Effects of an electrolyte additive on hydration and drinking behavior during wildfire suppression. Wilderness Environ Med. 2008;19(3):172-80.
20. National Interagency Fire Center. Boise, ID: National Interagency Mobilization Guide; 2020.

21. Navarro KM, Kleinman MT, Mackay CE, Reinhardt TE, Balmes JR, Broyles GA, et al. Wildland firefighter smoke exposure and risk of lung cancer and cardiovascular disease mortality. Environ Res. 2019;173:462-8.

22. Tanaka H, Monahan KD, Seals DR. Age-predicted maximal heart rate revisited. J Am Coll Cardiol. 2001;37(1):153-6.

23. Mosteller R. Simplified calculation of body-surface area. N Engl J Med. 1987;317(17):1098.

24. Buller MJ, Latzka WA, Yokota M, Tharion WJ, Moran DS. A real-time heat strain risk classifier using heart rate and skin temperature. Physiol Meas. 2008;29(12):N79-85.

25. Moran DS. Stress evaluation by the physiological strain index (PSI). J Basic Clin Physiol Pharmacol. 2000;11(4):403-23.

26. Moran DS, Shitzer A, Pandolf KB. A physiological strain index to evaluate heat stress. Am $J$ Physiol. 1998;275(1):R129-34.

27. Cuddy JS, Gaskill SE, Sharkey BJ, Harger SG, Ruby BC. Supplemental feedings increase self-selected work output during wildfire suppression. Med Sci Sports Exerc. 2007;39(6):1004-12.

28. Heil DP. Estimating energy expenditure in wildland firefighters using a physical activity monitor. Appl Ergon. 2002;33(5):405-13.

29. Rothfusz LP. The heat index equation. Fort Worth, TX: NWS Southern Region Technical Attachment; 1990. SR/SSD 90-23.

30. Cheung SS, Lee JK, Oksa J. Thermal stress, human performance, and physical employment standards. Appl Physiol Nutr Metab. 2016;41(6 Suppl 2):S148-64.

31. Kraning 2nd KK, Gonzalez RR. Physiological consequences of intermittent exercise during compensable and uncompensable heat stress. J Appl Physiol (1985). 1991;71(6):2138-45.

32. Périard JD, Caillaud C, Thompson MW. The role of aerobic fitness and exercise intensity on endurance performance in uncompensable heat stress conditions. Eur J Appl Physiol. 2012;112(6):1989-99.

33. Sawka NM, Wenger CB, Pandolf KB. Thermoregulatory responses to acute exercise-heat stress and heat acclimation. In: Handbook of Physiology. Environmental Physiology. Vol I. Bethesda, MD: American Physiological Society; 1996:157-85.

34. Tatterson AJ, Hahn AG, Martin DT, Febbraio MA. Effects of heat stress on physiological responses and exercise performance in elite cyclists. J Sci Med Sport. 2000;3(2):186-93.

35. Wendt D, van Loon LJ, van Marken Lichtenbelt WD. Thermoregulation during exercise in the heat: strategies for maintaining health and performance. Sports Med. 2007;37(8):669-82.

36. Drain J, Orr R, Attwells R, Billing D. Load carriage capacity of the dismounted combatant-A commander's guide. In: $\mathrm{HPaP}$ Division, ed. Defense Science and Technology Organization: Department of Defense. Australian Government; 2012. 
37. Cuddy JS, Buller M, Hailes WS, Ruby BC. Skin temperature and heart rate can be used to estimate physiological strain during exercise in the heat in a cohort of fit and unfit males. Mil Med. 2013;178(7):e841-7.

38. Gardner JW, Kark JA, Karnei K, Sanborn JS, Gastaldo E, Burr P, et al. Risk factors predicting exertional heat illness in male marine corps recruits. Med Sci Sports Exerc. 1996;28(8):939-44.
39. Guy JH, Deakin GB, Edwards AM, Miller CM, Pyne DB. Adaptation to hot environmental conditions: an exploration of the performance basis, procedures and future directions to optimise opportunities for elite athletes. Sports Med. 2015:45(3):303-11.

40. Marks AN, Sol JA, Domitrovich JW, West MR, Ruby BC. Total energy intake and self-selected macronutrient distribution during wildland fire suppression. Wilderness Environ Med. 2020;31(2):188-96. 